\title{
Application of the SPARROW Watershed Model to Describe Nutrient Sources and Transport in the Missouri River Basin
}

Spatially Referenced Regression On Watershed attributes (SPARROW) models were developed to provide spatially explicit information on local and regional total nitrogen and total phosphorus sources and transport in the Missouri River Basin. Model results provide estimates of the relative contributions from various nutrient sources and delivery factors. The models also describe instream decay and reservoir and lake attenuation of nutrients. Results aid in the prioritization of nutrient-reduction strategies by identifying major sources and delivery factors contributing to instream nutrient loads and stream reaches carrying the largest nutrient loads in the Missouri River Basin.

\section{Introduction}

Nutrient enrichment has been identified as one of the leading causes of water-quality impairment in rivers. Agricultural, urban, and industrial development has contributed to the nutrient enrichment of streams, reservoirs, and lakes in the Missouri River Basin. Understanding the sources and processes influencing nutrient transport in the Missouri River Basin has local, regional, and national implications for nutrient management efforts and can aid in the prioritization of nutrient-reduction strategies.

$\underline{\text { SPAtially }}$ Referenced $\underline{R}$ egression $\underline{\text { On }}$ Watershed attributes (SPARROW) models were developed for the Missouri River Basin (Brown and others, 2011) as part of a national effort to assess nutrient sources and transport in streams in six major regions in the conterminous United States, itself a part of the Status and Trends Program of the U.S. Geological Survey National Water Quality Assessment Program (NAWQA). The SPARROW model is a nonlinear regression model that relates annual nutrient loads computed from monitoring data to spatially-referenced watershed characteristics, such as nutrient sources and factors influencing terrestrial and aquatic transport (Schwarz and others, 2006). SPARROW models were used to relate instream nutrient loads of total nitrogen (nitrogen) and total phosphorus (phosphorus) to sources and factors influencing transport of nutrients in the Missouri River Basin (Brown and others, 2011). These models were developed for mean annual conditions in the early 2000 s.

SPARROW nutrient models for the Missouri River Basin were used to (1) identify and quantify the primary nutrient sources and terrestrial and aquatic delivery factors influencing nitrogen and phosphorus loads, (2) predict nitrogen and phosphorus loads (and yields and concentrations) and track their delivery to the Mississippi River, and (3) evaluate the effects of reservoir and lake attenuation and irrigated agricultural area on nutrient loads.

Applications of the SPARROW watershed model to describe nutrient sources and transport in the Missouri River Basin

The results of the Missouri River Basin SPARROW nitrogen and phosphorus models can be used to inform monitoring and management decisions:
- Describe major nutrient sources and transport processes throughout the Missouri River Basin-

- Nitrogen yields are highly variable and agricultural inputs from farm fertilizer and manure (fig. 1, yellow and orange bars) are the largest components of the nitrogen outlet yield in the seven major Missouri River subbasins.

- Atmospheric deposition (along the western boundary of the basin) and runoff from developed land (near larger urban areas) were found to be important nitrogen sources in some parts of the basin (fig. 1, inset map).

- Identify areas for nutrient monitoring - where predicted loads and yields are high, where prediction uncertainty is largest, or where available monitoring data are sparse.

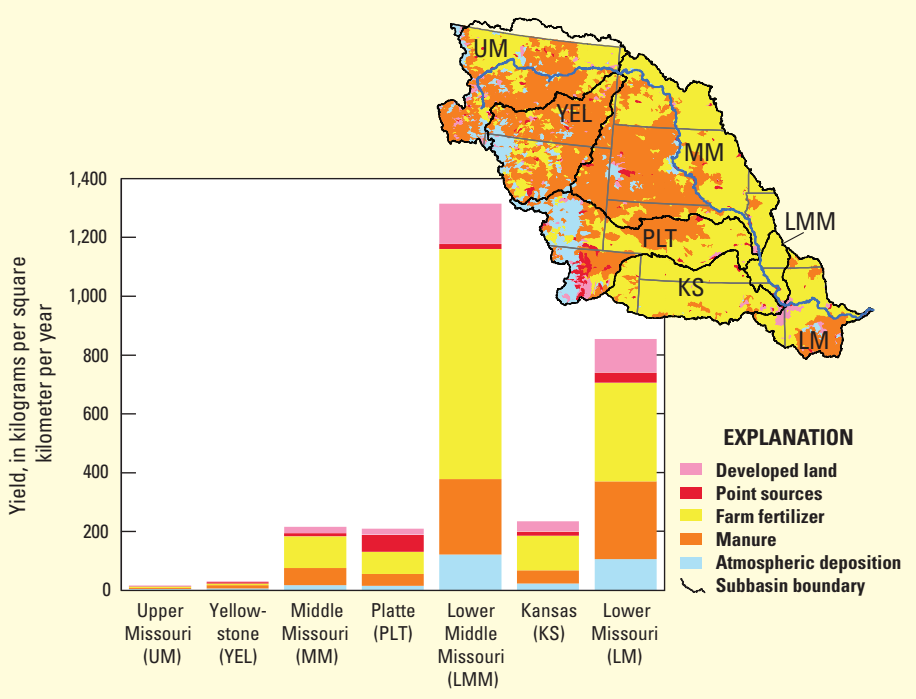

Figure 1. Predicted total nitrogen yields by primary source delivered to the major subbasin outlets (diagram), and geospatial distribution of primary sources (inset map), within an incremental catchment in the Missouri River Basin. For this figure, the primary source in each incremental catchment was defined as the source contributing the greatest percentage of the total load. Other sources are also usually present in each catchment but in smaller proportions. 
- Assess source-reduction scenarios - by altering sources in specific geographic areas (for example, selected catchments, subbasins, or counties) to evaluate local and downstream effects.

- The highest nitrogen yields delivered to the Mississippi River (fig. 2, right) were found in the southeastern part of the Missouri River Basin and in the Platte River subbasin (PLT in fig. 1, inset map).

- The catchments or subbasins with the largest nitrogen yields could be evaluated for various source-reduction scenarios to predict the downstream effect.

- Prioritize areas for nutrient-reduction strategies - by identifying catchments (local areas draining to a given stream reach) with high incremental loads or yields (or both).

- In the Missouri River Basin, the highest incremental nitrogen yields (fig. 2, left) were found in the southeastern part of the basin where there are more agricultural and point sources.
- Evaluate attenuation in streams, reservoirs, and lakes throughout the Missouri River Basin-

- Approximately 16 percent of the nitrogen load from the Missouri River is retained in reservoirs and lakes throughout the basin (fig. 3), and nearly half of the total attenuation occurs in the eight largest waterbodies.

- The remainder of the instream nitrogen was attenuated in streams flowing less than approximately 3.1 cubic meters per second (110 cubic feet per second).

\section{- Identify primary sources and land-to-water delivery} variables affecting nutrient loads, yields, and concentrations across the Missouri River Basin (fig. 4, next page).

\section{Incremental total nitrogen yield}

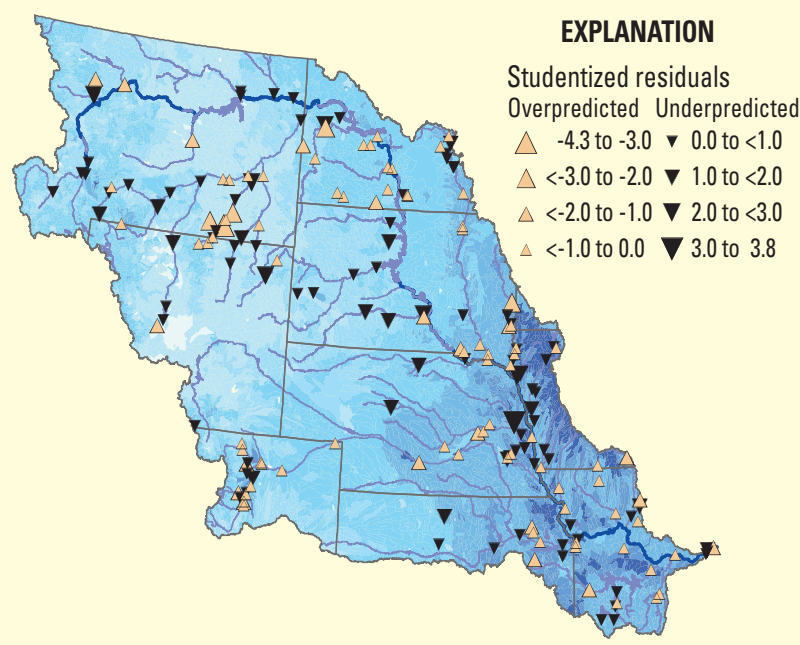

\section{Delivered total nitrogen yield}

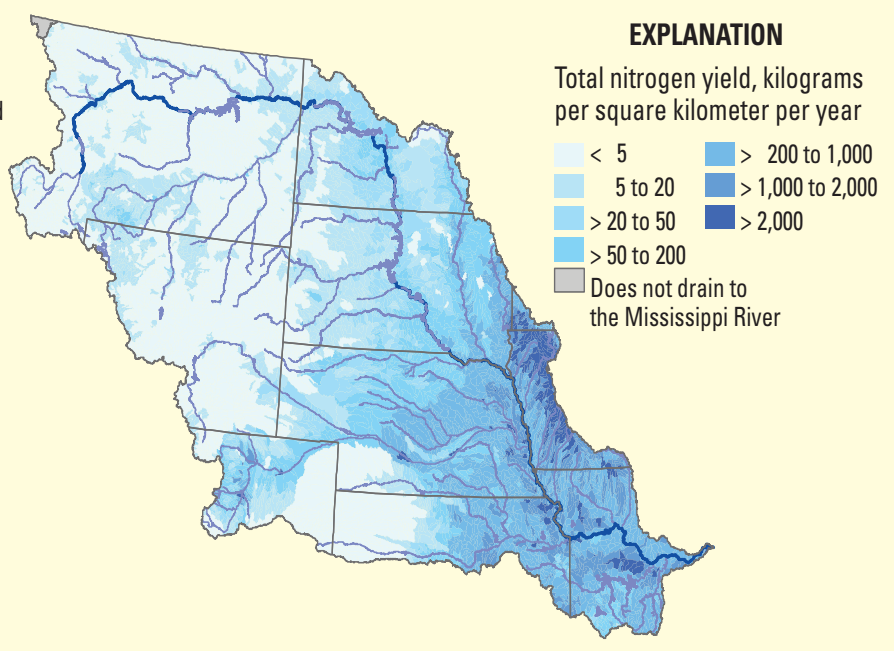

Figure 2. Predicted total nitrogen yields with model residuals for sites used to calibrate the SPARROW nitrogen model (left) and predicted total nitrogen yields delivered to the Mississippi River (right) from incremental catchments.

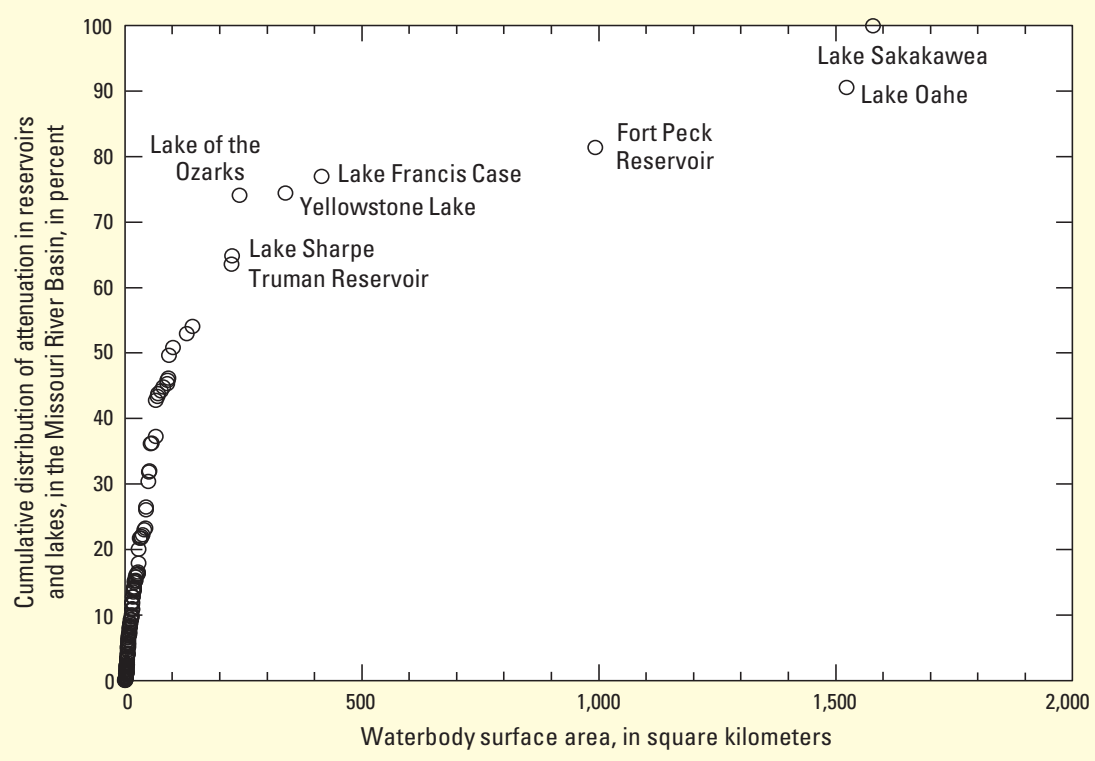

Figure 3. Cumulative distribution of attenuation of total nitrogen in reservoirs and lakes (based on a standard cumulative distribution ordered by increasing waterbody surface area). 


\section{Nitrogen Sources}

\section{Point sources}

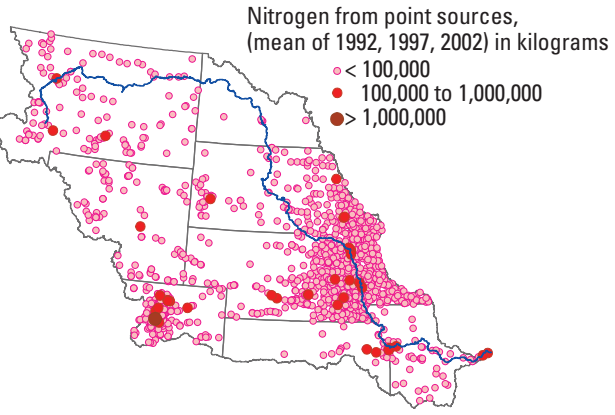

Atmospheric deposition

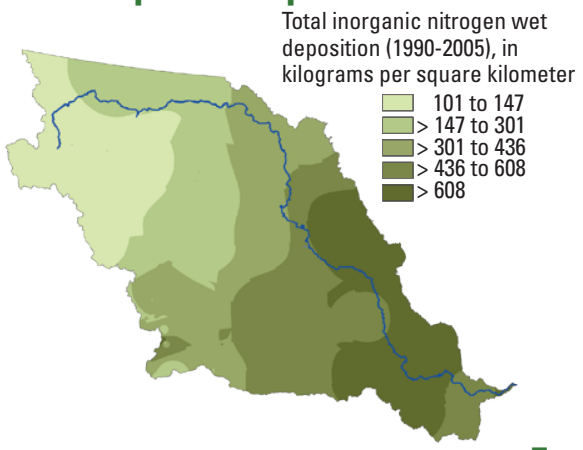

\section{Developed land area}

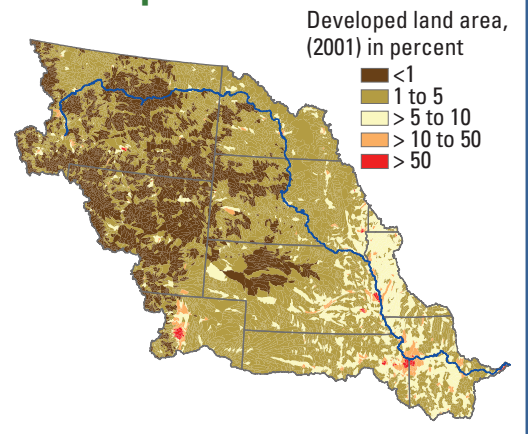

Manure

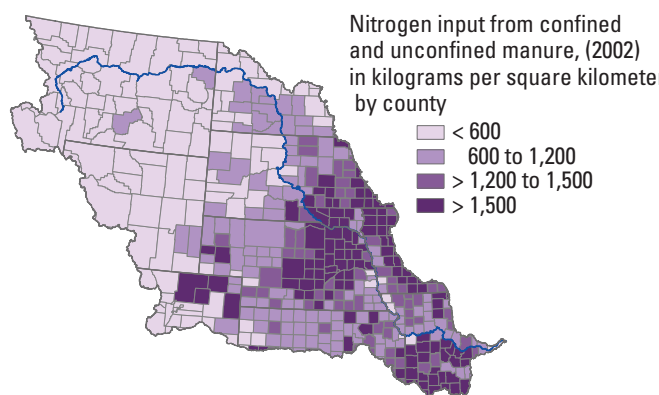

Farm fertilizer

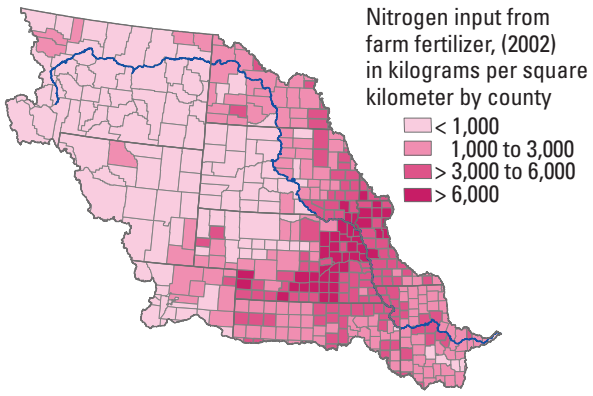

\section{Land-to-Water Delivery Factors}

\section{Percent irrigated area}

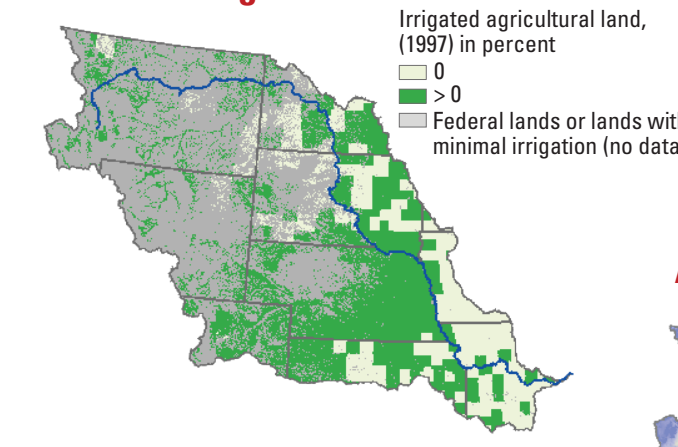

Air temperature

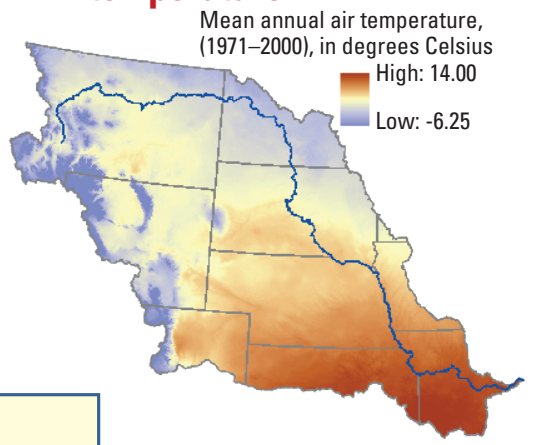

\section{Precipitation}

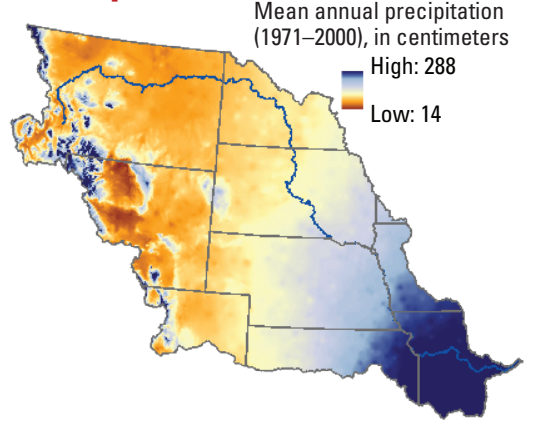

Percent loess

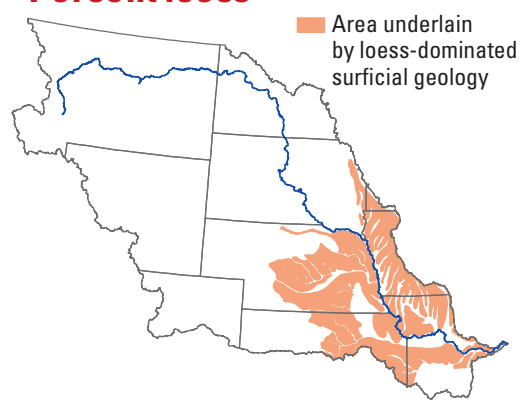

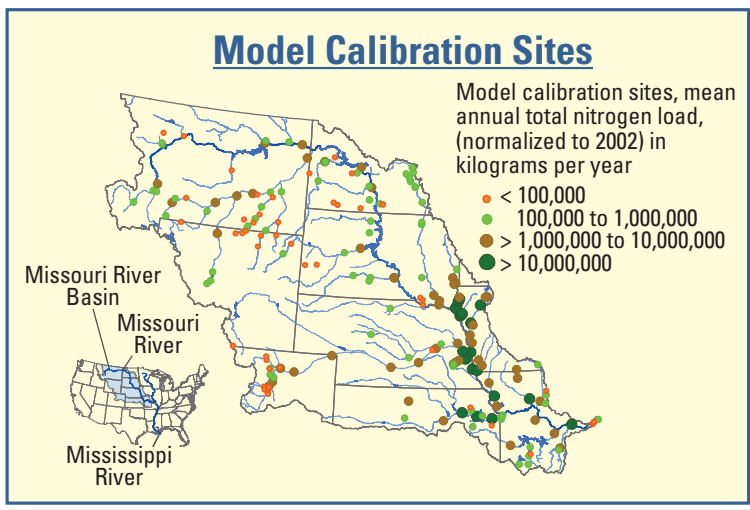

Figure 4. Total nitrogen sources and delivery factors in the Missouri River Basin SPARROW nitrogen model. 
Interactive SPARROW Decision Support System (DSS) is available to:

- Provide online access to national, regional, and basin-wide SPARROW data and model results (fig. 5).

- Evaluate management source-reduction scenarios.

- Track transport to downstream receiving waters, such as reservoirs, major river confluences, and estuaries.

- Map model predictions of long-term average water-quality conditions (loads, yields, and concentrations) and source contributions by stream reach and catchment.
- Overlay land use, shaded relief, street-level data, states, counties, and hydrologic units.

- Easily share scenarios with colleagues and stakeholders.

- Access the DSS at http://water.usgs.gov/nawqa/sparrow/dss.

- For more information see Booth and others (2011).

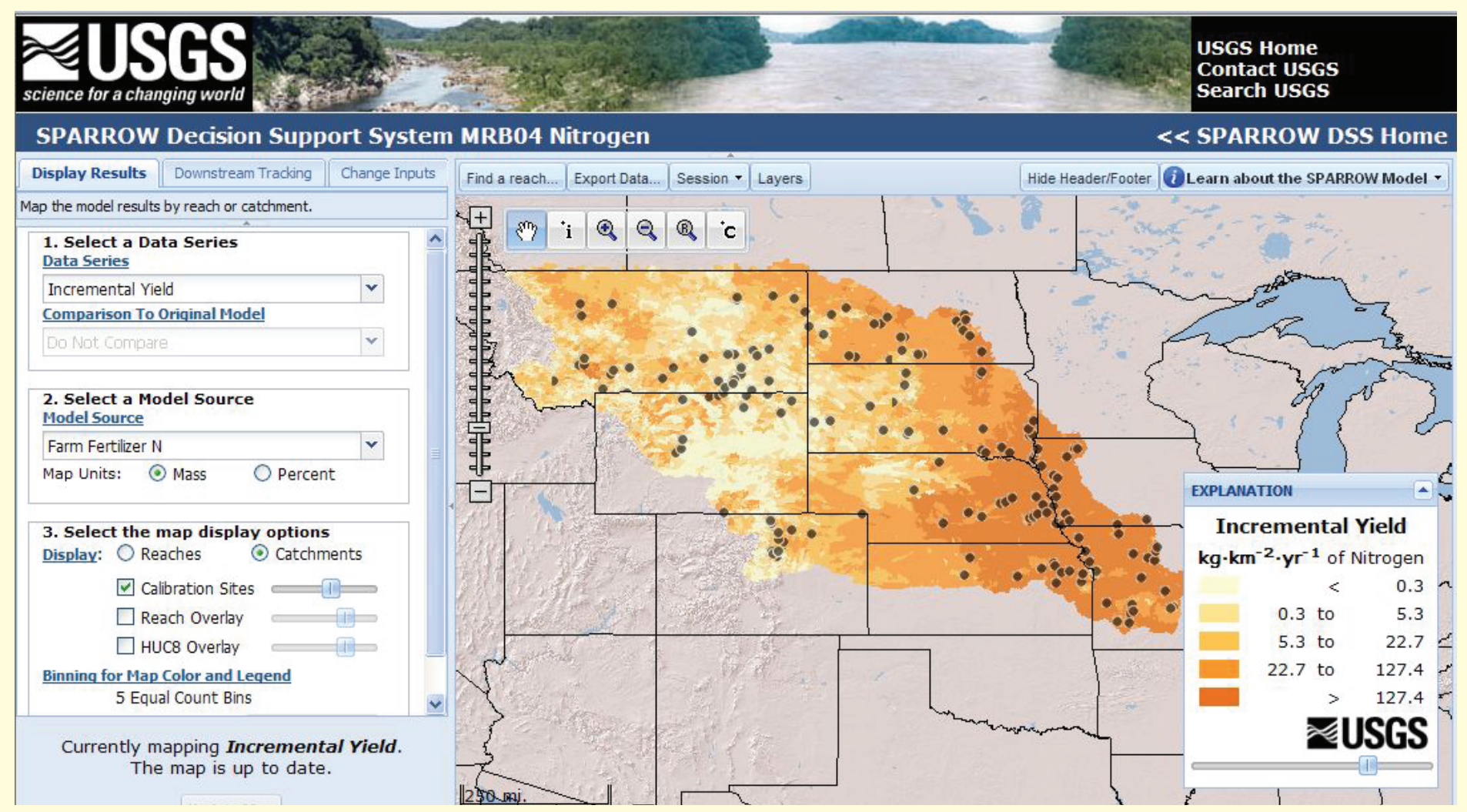

Figure 5. SPARROW Decision Support System.

\section{References Cited}

Booth, N.L., Everman, E.J., Kuo, I., Sprague, L.A., and Murphy, L., 2011, A web-based Decision Support System for accessing regional water-quality conditions and management actions: Journal of the American Water Resources Association, Paper no. JAWRA-10-0177-P, doi: 10.1111/j.17521688.2011.00573.x.

Brown, J.B., Sprague, L.A., and Dupree, J.A., 2011. Nutrient sources and transport in the Missouri River Basin, with emphasis on the effects of irrigation and reservoirs: Journal of the American Water Resources Association, Paper no. JAWRA-10-0167-P, 1-27. doi: 10.1111/j.17521688.2011.00584.x.
Schwarz, G.E., Hoos, A.B., Alexander, R.B., and Smith, R.A., 2006. The SPARROW surface water-quality model-Theory, application and user documentation. U.S. Geological Survey Techniques and Methods 6-B3, 248 p. and CD-ROM, accessed June 2011, at URL http://pubs.usgs.gov/tm/2006/tm6b3

\section{For Further Information}

More information on SPARROW is available online at $h t t p: / /$ water.usgs.gov/nawqa/sparrow/

For information on the Missouri River Basin SPARROW total nitrogen and total phosphorus models contact Juliane B. Brown (jbbrown@usgs.gov). 